\title{
FAKTOR-FAKTOR YANG MEMPENGARUHI KEBERSIHAN DIRI SELAMA MENSTRUASI PADA REMAJA PUTRI DI PONDOK PESANTREN YAYASAN NURUL ISLAM KABUPATEN BUNGO
}

\author{
Citra Indah Fitriwati ${ }^{1}$, Suhaela Arofah ${ }^{2}$ \\ ${ }^{1-2}$ Akademi Keperawatan Setih Setio Kabupaten Bungo, Jambi \\ Email: citra.indah.fitriwati@gmail.com
}

\begin{abstract}
ABSTRAK
Menstruasi merupakan proses pelepasan dinding rahim disertai pendarahan dan terjadi setiap bulan. Remaja putri yang sudah matang alat reproduksi maupun hormon- hormon dalam tubuhnya akan mengalami menstruasi. Kebersihan organ genetalia saat menstruasi perlu mendapat perhatian khusus bagi remaja putri agar terhindar dari pembusukan dan berkembangnya jamur sehingga bisa menimbulkan infeksi organ reproduksi dan infeksi organ perkemihan. Penelitian ini bertujuan untuk mengidentifikasi faktor-faktor yang mempengaruhi kebersihan diri selama menstruasi pada remaja putri di Pondok Pesantren Nurul Islam Kabupaten Bungo. Penelitian ini menggunakan desain cross sectional. Sampel dalam penelitian ini sebanyak 74 responden. Hasil penelitian menunjukkan bahwa terdapat hubungan yang signifikan antara faktor pengetahuan $(p$-value $=0,0005)$, faktor pola komunikasi orang tua $(p$-value $=0,004)$, faktor dukungan teman sebaya $(p$-value $=0,0005)$ dan faktor pengaruh budaya ( $p$-value $=0,0005$ ) dengan kebersihan diri selama menstruasi pada remaja putri. Tidak terdapat hubungan yang signifikan antara faktor pengaruh sikap $(p$-value $=0,124)$ dengan kebersihan diri selama menstruasi pada remaja putri. Saran yang dapat diberikan adalah sebaiknya di lingkungan pondok pesantren perlu meningkatkan edukasi terkait kebersihan diri selama menstruasi khususnya kesehatan reproduksi wanita yang bisa dikaitkan dengan pembelajaran di kelas. Metode penyampaian bisa melalui metode forum grup discussion.
\end{abstract}

Kata Kunci: kebersihan diri selama menstruasi, remaja putri, menstruasi

\begin{abstract}
Menstruation is the process of releasing the uterine with bleeding and occurs every month. Adolescent who are mature reproductive organs and hormones in their bodies will experience menstruation. The cleanliness of the genetal organs during menstruation needs special attention for adolescent to avoid decay and the development of fungi that can cause reproductive organ infections and urinary organ infections. This study aims to identify the factors that influence personal hygiene during menstruation in adolescent at Nurul Islam Islamic Boarding School, Bungo Regency. This study used a cross sectional design. The sample in this study were 74 respondents. The results showed that there was a significant relationship between knowledge factors ( $p$-value $=0.0005)$, parent communication pattern factors $(p$-value $=0.004)$, peer support factors $(p$-value $=0.0005)$ and culture factors $(p$-value $=$ $0.0005)$ with personal hygiene during menstruation in adolescent. There was no significant relationship between the influence factor of attitude ( $p$-value $=0.124)$ with personal hygiene during menstruation in young women. The suggestion that can be given is that it is better if the boarding school environment needs to increase education related to personal hygiene during menstruation,
\end{abstract}


especially women's reproductive health which can be linked to classroom learning. The delivery method can be through the group discussion forum method.

Keywords: Personal hygiene during menstruation, adolescent, menstruation

\section{LATAR BELAKANG}

Menurut World Health Organization (WHO), remaja adalah periode usia antara 10 sampai 19 tahun. Masa remaja adalah masa dimana terjadi peralihan dari masa anak menuju dewasa. Remaja secara umum dimulai ketika memasuki masa pubertas yaitu antara umur 10 - 24 tahun (Allender, Rector \& Warner, 2010). Masa remaja merupakan masa dimana terjadi perubahan tubuh (growth spurt), timbul ciri-ciri seks sekunder, tercapainya fertilitas dan terjadinya perubahan-perubahan psikologi serta kognitif (Setyaningrum dan Zulfa, 2014).

Perubahan fisik remaja merupakan ciri utama dari proses biologis yang terjadi pada masa pubertas. Pada masa ini terjadi perubahan fisik secara cepat, yang tidak seimbang dengan perubahan kejiwaan (mental emosional). Perubahan fisik yang terjadi termasuk pertumbuhan organ-organ reproduksi untuk mencapai kematangan agar mampu melangsungkan fungsi reproduksi (Rochmania, 2015). Perubahan fisik cukup terlihat ketika remaja memasuki usia antara 9-15 tahun, pada saat itu mereka tidak hanya tumbuh menjadi lebih tinggi dan lebih besar saja, tetapi terjadi juga perubahan-perubahan di dalam tubuh yang memungkinkan untuk berproduksi atau berketurunan. Perubahan dari masa kanak-kanak menuju masa dewasa atau sering dikenal dengan istilah masa pubertas ditandai dengan datangnya menstruasi pada perempuan (Setiyaningrum dan Zulfa, 2014).

Perubahan fisik cukup terlihat ketika remaja memasuki usia antara 9-15 tahun, pada saat itu mereka tidak hanya tumbuh menjadi lebih tinggi dan lebih besar saja, tetapi terjadi juga perubahan-perubahan di dalam tubuh yang memungkinkan untuk berproduksi atau berketurunan. Perubahan dari masa kanak-kanak menuju masa dewasa atau sering dikenal dengan istilah masa pubertas ditandai dengan datangnya menstruasi pada perempuan (Setiyaningrum dan Zulfa, 2014).

Menstruasi merupakan proses pelepasan dinding rahim disertai pendarahan dan terjadi setiap bulan. Menjaga kebersihan organ genetalia saat menstruasi perlu mendapat perhatian khusus agar terhindar dari pembusukan dan berkembangnya jamur (Maharani \& Adryani, 2018). Angka kejadian ISR di dunia pada usia remaja menempati posisi tertinggi yaitu sebesar 35\%-42\% dan pada usia dewasa muda sebesar 27\%-33\% (Rohidah, 2018). Prevalensi ISR pada remaja di dunia antara lain kandidiasis sebesar 25\%-50\%, vaginosis bakterial sebesar 20\%-40\% dan trikomoniasis sebesar 5\%-15\% (Puspitaningrum dkk, 2017). Penyakit infeksi di sistem reproduksi dapat disebabkan karena wanita kurang memelihara kebersihan diri pada saat menstruasi (White, 2010).

Masalah yang dihadapi wanita tiap bulannya berkaitan dengan menstruasi antara lain adalah mengalami keputihan sebanyak 19\%, rasa gatal pada area genital sebanyak $25 \%$, premenstrual sindrome $36 \%$, rasa tidak nyaman selama menstruasi $35 \%$, darah menstruasi yang sangat banyak 10\%, mengalami kram perut (Anand, Singh, \& Unisa, 2015). Menstruasi juga membuat remaja putri menjadi cemas, khawatir dan kurang percaya diri (Su \& Lindell, 2016). Salah satu penyebab keputihan adalah karena kebersihan diri selama menstruasi yang tidak bersih (Anand, Singh, \& Unisa, 2015). 
Kebersihan diri saat menstruasi pada remaja merupakan isu kritis sebagai determinan status kesehatan remaja yang akan berpengaruh dalam kehidupan masa tua. Buruknya kebersihan diri saat menstruasi berpengaruh besar terhadap morbiditas dan komplikasi (Uzochukwu, 2009). Pendidikan merupakan salah satu faktor yang berperan penting dalam meningkatkan kualitas sumber daya manusia, salah satunya pondok pesantren (Halima, dkk., 2014). Berdasarkan wawancara peneliti di Pondok Pesantren, pembahasan mengenai seksualitas masih dianggap tabu untuk dibicarakan di pesantren karena dianggap suci oleh sebagian masyarakat pesantren.

Kehidupan remaja putri di pesantren berbeda dengan remaja putri pada umumnya. Santriwati dituntut untuk beradaptasi dengan kegiatan dan peraturan di pesantren dengan jadwal padat yang harus diikuti santri. Dalam kegiatan pendidikan formal, peserta didik hanya belajar dan berinteraksi dengan teman serta guru kurang lebih 6-7 jam dalam satu hari, hampir 24 jam remaja berinteraksi dengan teman sebayanya di lingkungan pesantren (Machfutra, 2018). Penelitian ini bertujuan untuk mengidentifikasi faktor-faktor yang mempengaruhi kebersihan diri selama menstruasi pada remaja putri di Pondok Pesantren Nurul Islam Bungo.

\section{METODE PENELITIAN}

Jenis penelitian ini adalah adalah penelitian kuantitatif dengan pendekatan studi cross sectional. Data yang dikumpulkan dengan pendekatan cross sectional dikumpulkan dalam satu waktu. Penelitian ini dilakukan di Pondok Pesantren Nurul Islam Bungo dan dilaksanakan pada tanggal 10 Agustus - 31 Agustus 2020. Populasi dalam penelitian ini adalah seluruh remaja putri yang bersekolah di MTS dan SMK di Pondok Nurul Islam Bungo sejumlah 112 orang. Teknik pengambilan sampel dalam penelitian ini adalah purposive sampling. Sampel pada penelitian ini adalah siswi di Pondok Pesantren Nurul Islam Bungo dengan kriteria inklusi berumur 13-19 tahun, bersedia menjadi responden, siswi sudah mengalami menstruasi, serta hadir dalam penelitian. Adapun kriteria eksklusi siswi yang belum mengalami menstruasi.

Instrumen yang digunakan pada penelitian ini adalah pengembangan kuesioner Adolescent Menstrual Attitude Questionnaire (Morse, Kieren, \& Bottorff, 2009), terdiri dari 56 pertanyaan dengan sub bagian: perasaan positif, perasaan negatif, penerimaan terhadap menstruasi pertama, keterbukaan fikiran terhadap menstruasi, hidup dengan mestruasi dan gejala premenstrual sindrom. Selain itu, kuesioner dari penelitian Meinarisa (2019) tentang Pendidikan Kesehatan Menstrual Hygiene (PMH). Uji validitas pada instrumen penelitian ini valid dengan nilai $\mathrm{r}=0,361(\alpha=0.05)$. Analisa data dilakukan melalui tiga tahapan yaitu univariat untuk mendiskripsikan setiap variabel penelitian, analisa bivariat menggunakan korelasi dan Analisa multivariat dengan regresi linier. 


\section{HASIL DAN PEMBAHASAN}

\section{Analisis Univariat}

Berdasarkan penelitian didapatkan data sebagai berikut:

Tabel 1

Distribusi Responden Berdasarkan Umur Menarche dan Umur Sekarang

\begin{tabular}{ccccc}
\hline $\begin{array}{c}\text { Karakteristik } \\
\text { responden }\end{array}$ & Mean & SD & $\begin{array}{c}\text { Minimal- } \\
\text { maksimal }\end{array}$ & 95\% CI \\
\hline $\begin{array}{c}\text { Umur } \\
\text { menarche }\end{array}$ & 12,04 & 1,039 & $9-14$ & $11,80-12,28$ \\
\hline $\begin{array}{c}\text { Umur } \\
\text { sekarang }\end{array}$ & 14,08 & 1,542 & $12-17$ & $13,72-14,44$ \\
\hline
\end{tabular}

Berdasarkan tabel 1 diketahui bahwa rata-rata umur menarche responden adalah 12 tahun. Usia menarche termuda 9 tahun dan usia menarche tertua 14 tahun. Dari hasil estimasi interval dapat disimpulkan bahwa 95\% diyakini bahwa rata-rata umur menarche responden adalah 11,80 sampai dengan 12,28 tahun. Rata-rata umur responden sekarang adalah 14 tahun (95\% CI: 13,72-14,44). Usia responden yang termuda adalah 12 tahun dan usia responden yang tertua adalah 17 tahun. Dapat disimpulkan bahwa 95\% diyakini bahwa rata-rata umur responden adalah 13,72 sampai dengan 14,44 tahun.

Tabel 2

Distribusi Responden Berdasarkan Pendidikan Terakhir Ibu

\begin{tabular}{ccc}
\hline $\begin{array}{c}\text { Karakteristik } \\
\text { responden }\end{array}$ & $\mathbf{n}$ & $\%$ \\
\hline $\begin{array}{c}\text { Pendidikan Ibu } \\
\text { Tidak tamat SD }\end{array}$ & 1 & 1,4 \\
SD & 18 & 24,3 \\
SMP & 17 & 23 \\
SMA & 24 & 32,4 \\
PT & 14 & 18,9 \\
Total & 74 & 100 \\
\hline
\end{tabular}

Berdasarkan tabel 2, distribusi tingkat pendidikan ibu responden paling banyak berpendidikan terakhir SMA yaitu 24 orang $(32,4 \%)$ sedangkan Ibu responden yang berpendidikan terakhir di perguruan tinggi sebanyak 14 orang (18,9\%), SMP sebanyak 17 orang $(23 \%)$, SD sebanyak 18 orang $(24,3 \%)$ dan tidak tamat SD sebanyak 1 orang $(1,4 \%)$.

\section{Analisis Bivariat}

Hasil analisis bivariat adalah sebagai berikut.

Tabel 3

Hubungan kebersihan diri selama menstruasi dengan pengetahuan

\begin{tabular}{|c|c|c|c|c|c|c|}
\hline Variabel & $\frac{\text { Kebersihan }}{\text { Mean }}$ & $\begin{array}{l}\text { diri } \\
\text { SD }\end{array}$ & $\begin{array}{l}\text { Minimal- } \\
\text { maksimal }\end{array}$ & $95 \% \mathrm{CI}$ & $\mathbf{R}$ & P value \\
\hline Pengetahuan & 6,73 & 2,069 & $1-10$ & $\begin{array}{l}6,25- \\
7,21\end{array}$ & 0,768 & 0,0005 \\
\hline
\end{tabular}

Berdasarkan tabel 3 ini menunjukan bahwa rata-rata skor pengetahuan adalah 6,73 (95\% CI: 6,25-7,21) dengan standar deviasi 2,069. Rata-rata skor pengetahuan pada siswi terendah adalah 1 dan tertinggi 10. Dari hasil estimasi interval dapat disimpulkan bahwa 95\% 
CI diyakini bahwa rata-rata skor pengetahuan siswi adalah diantara 6,25-7,21. Uji statistik dengan korelasi menghasilkan nilai r 0,768 dan Nilai p value 0,0005. Kesimpulan dari hasil tersebut: hubungan kebersihan diri selama menstruasi dengan pengetahuan menunjukkan hubungan yang sangat kuat dan berpola positif artinya semakin bertambah pengetahuan semakin baik kebersihan diri selama menstruasi.

Tabel 4

Hubungan kebersihan diri selama menstruasi dengan sikap

\begin{tabular}{lcccccc}
\hline Variabel & \multicolumn{2}{c}{ Kebersihan diri } & \multicolumn{1}{c}{$\begin{array}{c}\text { Minimal- } \\
\text { maksimal }\end{array}$} & 95\% CI & r & P value \\
\cline { 2 - 5 } & Mean & SD & & $158,04-166,04$ & 0,18 & 0,124
\end{tabular}

Berdasarkan tabel 4 diketahui bahwa rata-rata skor sikap adalah 162,04 (95\% CI: 158,04-166,04). Rata-rata skor sikap pada siswi terendah adalah 127 dan tertinggi 212. Dari hasil estimasi interval dapat disimpulkan bahwa 95\% CI diyakini bahwa rata-rata skor sikap siswi adalah diantara 158,04 sampai dengan 166,04. Uji statistik dengan korelasi menghasilkan nilai $\mathrm{r} 0,18$ dan Nilai p value 0,124. Kesimpulannya tidak ada hubungan kebersihan diri selama menstruasi dengan sikap.

\section{Tabel 5}

Hubungan kebersihan diri selama menstruasi dengan pola komunikasi orang tua

\begin{tabular}{lllcccc}
\hline \multirow{2}{*}{ Variabel } & \multicolumn{2}{c}{ Kebersihan diri } & $\begin{array}{l}\text { Minimal- } \\
\text { maksimal }\end{array}$ & 95\% CI & r & P value \\
\cline { 2 - 7 } & Mean & SD & & 0,333 & 0,004 \\
$\begin{array}{l}\text { Pola } \\
\text { komunikasi } \\
\text { orangtua }\end{array}$ & 7,91 & 1,545 & $4-10$ & $7,55-8,26$ & & \\
\hline
\end{tabular}

Berdasarkan tabel 5 diketahui bahwa rata-rata skor pola komunikasi dengan orang tua adalah 7,91 (95\% CI: 7,55-8,26). Rata-rata skor pola komunikasi dengan orang tua terendah adalah 4 dan tertinggi 10. Dari hasil estimasi interval dapat disimpulkan bahwa $95 \%$ CI diyakini bahwa rata-rata skor pola komunikasi dengan orang tua adalah diantara 7,55 sampai dengan 8,26.

Uji statistik dengan korelasi menghasilkan nilai $\mathrm{r}$ 0,333 dan Nilai $\mathrm{p}$ value 0,004 . Kesimpulan dari hasil tersebut adalah ada hubungan kebersihan diri selama menstruasi dengan pola komunikasi orang tua.

Tabel 6

Hubungan kebersihan diri selama menstruasi dengan dukungan teman sebaya

\begin{tabular}{|c|c|c|c|c|c|c|}
\hline \multirow[t]{2}{*}{ Variabel } & \multicolumn{2}{|c|}{ Kebersihan । diri } & \multirow{2}{*}{$\begin{array}{l}\text { Minimal- } \\
\text { maksimal }\end{array}$} & \multirow[t]{2}{*}{ 95\% CI } & \multirow[t]{2}{*}{$\mathbf{r}$} & \multirow{2}{*}{ P value } \\
\hline & Mean & SD & & & & \\
\hline $\begin{array}{l}\text { Dukungan } \\
\text { teman } \\
\text { sebaya }\end{array}$ & 7 & 1,526 & $3-10$ & $6,65-7,35$ & 0,756 & 0,0005 \\
\hline
\end{tabular}

Berdasarkan tabel 6 diketahui bahwa rata-rata skor dukungan teman sebaya adalah 7 (95\% CI: 6,65-7,35). Rata-rata skor dukungan teman adalah 3 dan tertinggi 10. Dari hasil estimasi interval dapat disimpulkan bahwa 95\% CI diyakini bahwa rata-rata skor dukungan teman adalah diantara 6,65 sampai dengan 7,35. Uji statistik dengan korelasi menghasilkan nilai $\mathrm{r}$ 0,756 dan nilai $\mathrm{p}$ value 0,0005. Artinya ada hubungan kebersihan diri selama menstruasi dengan dukungan teman.

Rata-rata skor pengaruh budaya adalah 6,8 (95\% CI: 6,37-7,22). Rata-rata skor pengaruh budaya terendah adalah 2 dan tertinggi 10. Dari hasil estimasi interval dapat disimpulkan bahwa 95\% CI diyakini bahwa rata-rata skor pengaruh budaya adalah diantara 
6,37 sampai dengan 7,22. Uji statistik dengan korelasi menghasilkan nilai r 0,711 dan nilai $\mathrm{p}$ value 0,0005. Kesimpulannya ada hubungan kebersihan diri selama menstruasi dengan pengaruh budaya (Tabel 7).

Tabel 7

Hubungan kebersihan diri selama menstruasi dengan budaya

\begin{tabular}{|c|c|c|c|c|c|c|}
\hline \multirow[t]{2}{*}{ Variabel } & \multicolumn{2}{|c|}{ Kebersihan di diri } & \multirow{2}{*}{$\begin{array}{l}\text { Minimal- } \\
\text { maksimal }\end{array}$} & \multirow[t]{2}{*}{$95 \% \mathrm{CI}$} & \multirow[t]{2}{*}{$\mathbf{r}$} & \multirow[t]{2}{*}{ P value } \\
\hline & Mean & SD & & & & \\
\hline Budaya & 6,8 & 1,843 & $2-10$ & $6,37-7,22$ & 0,711 & 0,0005 \\
\hline
\end{tabular}

Analisis multivariat

Analisis multivariat dalam penelitian ini mengunakan regresi linier.

Tabel 8

Seleksi bivariat faktor yang memengaruhi kebersihan diri selama menstruasi

\begin{tabular}{ccc}
\hline No & Variabel & P value \\
\hline 1 & Pengetahuan & 0,003 \\
\hline 2 & Sikap & 0,859 \\
\hline 3 & Pola komunikasi orang tua & 1 \\
\hline 4 & Dukungan teman sebaya & 0,02 \\
\hline 5 & Pengaruh budaya & 0,023 \\
\hline
\end{tabular}

Berdasarkan tabel 8 , hasil analisis bivariat dengan korelasi didapatkan nilai $\mathrm{p}$ value untuk variabel pengetahuan $(\mathrm{p}=0,003)$, sikap $(\mathrm{p}=0,859)$, pola komunikasi orang tua $(\mathrm{p}=1)$, dukungan teman sebaya $(\mathrm{p}=0,02)$, pengaruh budaya $(\mathrm{p}=0,023)$. Variabel yang memiliki $\mathrm{p}$ value $<0,25$ adalah variabel pengetahuan, dukungan teman sebaya dan pengaruh budaya. Maka ketiga variabel tersebut dapat lanjut masuk ke pemodelan multivariat.

Dari hasil statistik di dapatkan $p$ value $=0,0005$ berarti persamaan garis regresi secara keseluruhan sudah signifikan. Hasil uji F menunjukkan nilai $\mathrm{p}=0,000$. Artinya pada alpha 5\% dapat menyatakan bahwa model regresi cocok dengan data yang ada.

Setelah di lakukan analisis, variabel dependen yang masuk model akhir regresi adalah pengetahuan dan pola komunikasi orang tua tertera dalam tabel 9 dibawah ini.

Tabel 9 Model Akhir Regresi Linier

\begin{tabular}{cccc}
\hline Model & B & Beta & P value \\
\hline constant $)$ & 73,229 & & 0,000 \\
\hline Pengetahuan & 6,087 & 0,741 & 0,000 \\
\hline $\begin{array}{c}\text { Pola } \\
\text { komunikasi } \\
\text { orang tua }\end{array}$ & 0,925 & 0,079 & 0,328 \\
\hline
\end{tabular}

Variabel yang paling besar pengaruhnya terhadap kebersihan diri selama menstruasi pada siswi Pondok Pesantren Nurul Islam adalah pengetahuan.

\section{Hubungan kebersihan diri selama menstruasi dengan pengetahuan.}

Kebersihan diri pada saat menstruasi tidak akan terjadi begitu saja, namun merupakan sebuah proses yang dipelajari karena individu mengerti dampak positif atau negatif terhadap perilaku yang terkait dengan keadaan menstruasi (Indriastuti, 2009). Banyak faktor yang berpengaruh terhadap kebersihan diri selama menstruasi. Diantara faktor tersebut yakni pengetahuan individu. Hal tersebut sesuai dengan hasil analisis dalam penelitian ini.

Berdasarkan hasil analisis hubungan antara pengetahuan tentang menstruasi dengan kebersihan diri selama menstruasi menggunakan analisis korelasi di peroleh nilai $p=0,0005$ 
$(p<0,05)$ yang berarti bahwa pengetahuan tentang menstruasi memiliki hubungan yang signifikan dengan kebersihan diri selama menstruasi pada remaja putri di Pondok Pesantren Nurul Islam.

Hal ini sesuai dengan teori Patricia (2005), bahwa dalam kebersihan diri terdapat faktor yang berpengaruh diantaranya pengetahuan yang dimiliki oleh individu tersebut. Pengetahuan yang dimaksudkan merupakan pengetahuan yang bersangkutan dengan kebersihan diri diantaranya pengetahuan tentang menstruasi, pengetahuan kesehatan reproduksi pada wanita dan pengetahuan mengenai kebersihan diri pada wanita baik saat menstruasi maupun dalam keseharian.

Hasil penelitian ini didukung oleh penelitian Rahmawati (2011) bahwa pengetahuan tentang menstruasi berpengaruh terhadap perilaku kebersihan diri selama menstruasi pada siswi remaja. Hal yang sama juga diperoleh dari hasil penelitian Suryati (2012) yang mengungkapkan terdapat beberapa faktor yang berperan dalam perilaku kebersihan remaja saat menstruasi, diantara faktor tersebut yakni pengetahuan. Hal tersebut juga didukung dengan penelitian yang dilakukan oleh Prasetya (2014), bahwa pengetahuan menstruasi memiliki hubungan dengan personal hygiene selama menstruasi pada siswa kelas X SMA Negeri 2 Banguntapan Bantul dengan hasil uji hipotesis product moment $p=0,001(p<0,05)$.

\section{Hubungan kebersihan diri selama menstruasi dengan sikap}

Hasil penelitian ini menunjukkan tidak ada hubungan antara kebersihan diri selama menstruasi dengan sikap. Sejalan dengan penelitian Husni dan Pauzan (2016), yang menyebutkan tidak ada hubungan secara signifikan antara sikap dengan tindakan personal hygiene saat menstruasi di SMAN 2 Kota Bengkulu (nilai $\mathrm{p}=0,975$ ). Selain itu pada penelitian Wibowo (2006), menyebutkan bahwa sebagian besar remaja putri mempunyai sikap tidak mendukung (unfavorable) tidak senang mendapatkan menarche $(51,24 \%)$. Hal ini dikarenakan perlunya upaya dalam membentuk sikap yang mendukung tentang menstruasi. Menurut Notoatmodjo (2012), faktor-faktor yang mempengaruhi pembentukan sikap, yaitu pengalaman pribadi, kebudayaan, pengaruh orang yang dianggap penting, media massa, institusi dan agama serta faktor emosional.

Meinarisa (2019) menyebutkan bahwa sikap remaja putri dalam menjaga kebersihan selama menstruasi dipengaruhi oleh pendidikan kesehatan menstrual hygiene (PMH). Pemberitahuan informasi melalui pendidikan dan penyuluhan akan meningkatkan pengetahuan, yang selanjutnya akan menimbulkan kesadaran dan pada akhirnya remaja akan berperilaku sesuai dengan pengetahuan yang dimiliki, yang tentunya memerlukan waktu yang cukup lama. Sebelum remaja berperilaku positif tentang personal hygiene saat menstruasi, ia harus terlebih dahulu tahu apa arti dan manfaat tindakan tersebut bagi dirinya, selanjutnya akan menilai atau bersikap.

\section{Hubungan kebersihan diri selama menstruasi dengan pola komunikasi orang tua}

Menurut Efendy (2013), faktor yang berpengaruh terhadap komunikasi antara lain penyampaian pesan, situasi dan kondisi, media, tujuan pesan. Menurut Rakhmad (2007) bahwa pola-pola komunikasi interpersonal mempunyai efek yang berlainan pada hubungan interpersonal. Faktor-faktor yang mempengaruhi komunikasi interpersonal yakni percaya, sikap sportif, dan sikap terbuka. Efektifitas komunikasi interpersonal seperti yang dikemukakan oleh Devito (2011) yaitu karena adanya keterbukaan, empati, sikap mendukung, sikap positif dan kesetaraan.

Hasil penelitian ini menunjukkan ada hubungan antara kebersihan diri selama menstruasi dengan pola komunikasi orang tua. Komunikasi antar ibu dan anak akan memberikan informasi yang lebih mudah dipahami (Yusuf, 2014). Penelitian Fajri dan 
Khairani (2010) menjelaskan bahwa komunikasi memberikan peran sebesar 30\% terkait kesehatan. Pendidikan kesehatan reproduksi penting disampaikan kepada remaja putri terlebih kebersihan genetalia ketika menstruasi.

\section{Hubungan kebersihan diri selama menstruasi dengan dukungan teman sebaya}

Faktor lain yang cukup erat berhubungan dengan kebersihan diri selama menstruasi yaitu faktor eksternal. Lingkungan dan sosial sebagai faktor eksternal sangat mendukung terhadap perubahan kebersihan diri individu, dikarenakan lingkungan sebagai tempat perkembangan perilaku individu (Sunaryo, 2013).

Perkembangan kehidupan sosial remaja ditandai dengan meningkatnya pengaruh teman sebaya. Remaja lebih banyak menghabiskan waktunya untuk berinteraksi sosial dengan teman sebayanya. Teman sebaya memberikan pengaruh yang besar terhadap sikap, minat, penampilan dan perilaku remaja. Hal tersebut dikarenakan komu-nikasi diantara teman sebaya lebih mudah dicerna dan diterima daripada komunikasi dengan orang tua atau yang lebih dewasa daripada remaja (Desmita, 2009).

Hasil penelitian ini, terhadap 74 remaja putri di Pondok Pesantren Nurul Islam menggunakan analisis korelasi diperoleh $\mathrm{p}=0,0005(\mathrm{p}<0,05)$ yang berarti terdapat hubungan yang signifikan antara dukungan teman sebaya dengan kebersihan diri selama menstruasi. Hasil analisis tersebut sesuai dengan teori Hovland bahwa komunikasi merupakan sebuah proses dalam mengubah perilaku orang lain seperti halnya personal hygiene selama menstruasi (Efendy, 2011).

Hal tersebut juga didukung dengan penelitian yang dilakukan oleh Lestari, Prastya (2014), terhadap 102 siswi kelas X SMA Negeri 2 Banguntapan bantul bah-wa terdapat hubungan komunikasi teman sebaya dengan personal hygiene selama menstruasi dengan hasil uji $\mathrm{p}=0,000(\mathrm{p}<0,05)$, yang berarti bahwa terdapat hubungan yang signifikan antar variabel tersebut.

Hasil penelitian yang dilakukan peneliti juga didukung oleh penelitian Suryati (2012) di Jakarta yang berkaitan dengan perilaku kebersihan remaja saat menstruasi, yang menunjukkan bahwa terdapat hubungan yang signifikan antara dukungan teman sebaya dengan perilaku kebershan siswi pada saat menstruasi. Dukungan teman sebaya terhadap responden sebesar $86 \%$, dari hasil analisis bivariat didapatkan hasil $\mathrm{p}=0,024$, hasil analisis multivariat didapatkan ada hubungan antara teman sebaya dengan perilaku kebersihan saat menstruasi pada penelitian ini dengan nilai $\mathrm{p}=0,027$ dan nilai $\mathrm{OR}=2,963$ artinya bahwa dukungan teman sebaya 2,963 kali kemungkinan teman sebaya mendukung. Juyal et al (2012) dalam penelitian mengenai menstruasi didapatkan hasil bahwa 31,8\% remaja mendapatkan informasi pertama mengenai menstruasi dari teman. Sama halnya dengan Khan (2012) sumber informasi utama pengetahuan menarche didapatkan dari teman.

\section{Hubungan kebersihan diri selama menstruasi dengan pengaruh budaya}

Hasil penelitian ini menunjukkan ada hubungan yang kuat antara kebersihan diri selama menstruasi dengan pengaruh budaya. Penelitian ini sejalan dengan penelitian yang dilakukan oleh Santina et al (2013) pada remaja putri usia 13-19 tahun di Lebanon bahwa terdapat hubungan yang signifikan antara praktik menstrual hygiene berdasarkan sosial budaya.

Penelitian lain yang dilakukan oleh Patil (2014) di Desa Tirupati, Chandragiri, Renigunta dan Pakala India menemukan bahwa nilai rata-rata kebersihan menstruasi tampak pada remaja yang hanya sedikit mengikuti tradisi budaya terkait beberapa pembatasan 
melakukan hal-hal tertentu dibandingkan dengan mereka yang banyak mengikuti pembatasan selama menstruasi. Selain itu, penelitian Ety, Suriah, Fairus (2019) menggambarkan keyakinan masyarakat Suku Nuaulu Kabupaten Maluku Tengah terkait aturan-aturan yang ada dalam budaya mereka tentang perilaku personal hygiene remaja putri yakni larangan mandi dan mengganti kain pembalut selama menstruasi serta melumuri arang dapat menghilangkan bau badan serta memutihkan kulit. Pengaruh budaya tersebut menyebabkan mereka memiliki keterbatasan dalam berperilaku positif terhadap kesehatan khususnya kebersihan diri selama menstruasi.

Sebagian masyarakat misalnya menstruasi dianggap darah kotor sehingga seorang wanita harus diasingkan dan menjalani aktivitas harian di dalam rumah adat khusus untuk wanita yang tengah menstruasi. Perbedaan dalam mitos-mitos budaya membuat beberapa komunitas masyarakat juga berbeda dalam personal hygiene saat menstruasi (Maharani \& Adriyani, 2018).

\section{SIMPULAN DAN SARAN}

\section{Simpulan}

Berdasarkan hasil analisis dan pembahasan dapat disimpulkan bahwa factor yang mempengaruhi kebersihan diri selama menstruasi pada remaja putri di Pondok Pesantren Yayasan Nurul Islam Kabupaten Bungo antara lain pengetahuan, pola komunikasi orang tua, dukungan teman sebaya dan pengaruh budaya. Faktor yang paling besar pengaruhnya terhadap kebersihan diri selama menstruasi pada remaja putri di Pondok Pesantren Nurul Islam adalah faktor pengetahuan.

\section{Saran}

Penyelenggara pendidikan diharapkan dapat meningkatkan pengetahuan kesehatan reproduksi remaja putri terutama yang berhubungan dengan menstruasi melalui komunikasi teman sebaya guna meningkatkan personal hygiene selama menstruasi. Implementasi ini bisa dikaitkan dengan pembelajaran di kelas pada mata pelajaran yang bersangkutan misalnya penjaskes, biologi dan pendidikan agama. Metode alternatif dalam penyampaian pendidikan dan promosi kesehatan yang berbasis pada permasalahan kesehatan reproduksi remaja khususnya personal hygiene selama menstruasi melalui metode forup group discussion, peer grup discussion, peer teaching dan lain-lain.

\section{DAFTAR PUSTAKA}

Allender, J.A. Rector, C. Warner, K.D. (2010). Community Health Nursing Promoting \& Protecting the Public's Health 7th Edition. Philadelphia: Lippincott Williams \& Wilkins.

Anand, E., Singh, J., \& Unisa, S. (2015). Menstrual hygiene practices and its association with reproductive tract infections and abnormal vaginal discharge in India. Sexual \& Reproductive Healthcare, 1-6. http://doi.org/10.1016/j.srhc.2015.06. 001.

Desmita. (2009). Psikologi Perkembangan Peserta Didik. Bandung: PT Remaja Rosdakarya.

Devito, Joseph A. (2011). Komunikasi Antar Manusia. Pamulang-Tangerang Selatan: Karisma Publishing Group.

Effendy. (2011). Ilmu Komunikasi Teori dan Praktik. Bandung: PT. Remaja Rosdakarya. 
Halima S, Rahman MA, Riskiyani S. (2014). Persepsi Remaja tentang Kesehatan Reproduksi di Pondok Pesantren Manahilil Ulum Hidayiah Kaballangang Kabupaten Pinrang. Jurnal AKK, 3(1): 41-47.

Husni, Pauzan. 2016. Hubungan pengetahuan dan sikap dengan tindakan personal hygiene saat menstruasi pada remaja putri. Jurnal Media kesehatan Vol. 9 No. 2: 114-203.

Indriastuti, D.P. (2009). Hubungan antara Pengetahuan Kesehatan Reproduksi dengan Perilaku Higienis Remaja Putri pada Saat Menstruasi. Surakarta: UMS.

Juyal R., Kandpal SD, Semwal J, Negi KS. (2012). Practice of menstrual hygiene among adolescent girls in district of Uttarakand. Indian journal of community health $\mathrm{Vol} 24(2)$, 124-128.

Khan, A. (2012). Perceptions and Practice about Menstrual Hygiene among Adolescent Girls in a Rural Area - A Cross Sectional Study. International Journal of Health Science \& Research Vol 2(8), 29-34.

Lestari, Prasetya. (2014). Hubungan pengetahuan menstruasi dan komunikasi teman sebaya dengan personal hygiene selama menstruasi pada siswa SMA. Thesis. Depok : FIK UI.

Machfutra ED, Noor A, Asropi A, Luxiarti R, Mutmainah NF. (2018). Perilaku Hidup Bersih dan Sehat Santri Putri Pesantren X Yogyakarta. Bul Penelit Sist Kesehat. 21(4):236246.

Maharani, R., \& Andryani, W. (2018). Faktor Yang Berhubungan dengan Perilaku Personal Hygiene Saat Menstruasi pada Santriwati di MTs Pondok Pesantren Dar El Hikmah Kota Pekanbaru. KESMARS: Jurnal Kesehatan Masyarakat, Manajemen dan Administrasi Rumah Sakit, 1(1), 69-77. https://doi.org/10.31539/kesmars.v1i1.172

Meinarisa (2019). Pengaruh Pendidikan Kesehatan Menstrual Hygiene (PMH) Terhadap Sikap Remaja Putri Dalam Menjaga Kebersihan Diri Selama Menstruasi. Journal endurance: Kajian Ilmiah Problema Kesehatan Vol 4(1), 141-149. http://doi.org/10.22216/jen.v4i1.3542

Morse, J. M., Kieren, D., \& Bottorff, J. (2009). Health Care for Women International The adolescent menstrual attitude questionnaire, (January 2015), 37-41. http://doi.org/10.1080/073993393095.16025

Notoatmodjo. (2012). Promosi kesehatan dan perilaku kesehatan. Jakarta: Rineka Cipta

Patil S, R. (2014). Knowledge and practice of menstrual hygiene among married adolescents and young women in Chittoor District of Andra Pradesh: India. IOSR Journal of Nursing and Health Science (IOSR-JNHS) Volume 3(2), 06-15. Diakses tanggal 05 November 2020.

Patricia. (2005). Buku Ajar fundamental Keperawatan konsep Edisi 4. Jakarta: EGC.

Puspitasari, Fitria (2017). Pengetahuan, Sumber Informasi, Umur, Kepercayaan Terhadap Perilaku Personal Hygiene Pada Remaja Putri SMAN 1 Megamendung. Jurnal Ilmu Kesehatan Masyarakat, Vol (06), 04.

Puspitaningrum, W, Farid Agusybana, Atik Mawarni, dan Djoko Nugroho. 2017. Pengaruh Media Booklet Terhadap Pengetahuan Dan Sikap Remaja Putri Terkait Kebersihan Dalam Menstruasi Di Pondok Pesantren Al Ishlah Demak Triwulan Ii Tahun 2017. Jurnal Kesehatan Masyarakat. 5 (4): 274-281.

Rakhmat, Jalaluddin. (2007). Psikologi Komunikasi. Bandung: Remaja Rosdakarya.

Rahmawati T, Kusmawati. (2011). Hubungan antara Sumber Informasi dan Pengetahuan Tentang Menstruasi dengan Perilaku Personal Hygiene selama Menstruasi. Prosiding Seminar Nasional "Peran Kesehatan Masyarakat Dalam Pencapaian MDG's di Indonesia. FKM UNSIL Lampung. 
Rochmania, Bella Kartini. 2015. Sikap Remaja Putri dalam Menghadapi Perubahan Fisik Masa Pubertas. Jurnal Promkes Volume 3(2), 206-217. Departemen Kesehatan dan Ilmu Perilaku Fakultas Kesehatan Masyarakat.

Rohidah, Shofy., Nurmaliza. (2019). Hubungan Tingkat Pengetahuan Remaja Putri terhadap Personal Hygiene saat Menstruasi di SMA Negeri 3 Pekanbaru. Jurnal of Midwifery Science Volume 3(1), 32-35.

Santina, et al. (2013). Assessment of Beliefs and Practices Relating to Menstrual Hygiene of Adolescent Girls in Lebanon. Internasional Journal of Health Sciences and Research (IJHSR). ISSN: 2249-9571, Vol 3; Issue:12, Desember 2013.

Setiyaningrum E, Zulfa. (2014). Pelayanan Keluarga Berencana dan Kesehatan Rerpoduksi. Jakarta: CV. Trans Info Media.

Su, J. J., \& Lindell, D. (2016). Promoting the menstrual health of adolescent girls in China. Nursing \& health sciences, 18(4), 481-487.

Sunaryo. (2013). Psikologi untuk keperawatan. Ed.2. Jakarta: EGC.

Suryati. (2012). Perilaku Kebersihan Remaja Saat Menstruasi. Heal Qual, 3 (1):54-65.

Uzochukwu. (2009). The Impact of Premenarcheal Training on Menstrual Practice and Hygiene Of Nigerian School Girls. Pan Afr. Med. J.22

Yusuf, Y., Kundre, R., Rompas, S. (2014). Hubungan Pengetahuan Menarche dengan Kesiapan Remaja Putri Menghadapi Menarche di SMP Negeri 3 Tidore Kepulauan. https://e journal. Unsrat. Ac. Id/Index. Php/Jkp/Article/View/5272. 